Check for updates

Coventry and Warwickshire Health and Care Partnership

chrisham01@aol.com

Cite this as: BMJ 2020;371:m4973

http://dx.doi.org/10.1136/bmi.m4973

Published: 31 December 2020

\section{The challenges facing the NHS in England in 2021}

\section{An ambitious programme encompassing social care and health inequalities is needed \\ Chris Ham chair}

The NHS in England faces unprecedented challenges in 2021. It will require an equally unprecedented, and long term, response from the government to do two things-first to deal with the backlog of both physical and mental healthcare that the pandemic has caused, and second to create a system of health and care that tackles both the health inequalities and the other weaknesses that covid-19 has exposed.

The immediate challenge is the resurgence of covid-19 resulting in more patients being admitted to hospital with the virus than at the previous peak in April. At the same time, the NHS is being asked to deliver the biggest and most ambitious vaccine campaign in its history, while also developing services for patients with long covid.

Care for non-covid conditions is, once again, being scaled back and in some areas is likely to cease, at least temporarily. The result will be longer waiting times for diagnosis and treatment on top of the backlog that the pandemic caused in 2020 .

Eliminating waits of over 52 weeks -162 ooo of them at the last count ${ }^{1}$-and meeting the broader standard of 18 weeks for elective care will take years, not months.

The effect of covid-19 on mental health and wellbeing has been substantial. Services already under pressure have been stretched further in the face of rising demand from children and adults. The long term effects are likely to be considerable, with one estimate indicating that up to 10 million people will require new or additional mental health support. ${ }^{2}$

Staff absence, caused by both infections and the need to self-isolate, is currently having a material effect on the ability of the NHS to care for patients with the virus, as well as those without it. The same is true in care homes and in domiciliary care. Reports of hospitals asking staff to cancel or restrict planned leave is an indication of the pressures facing services.

Looking to the longer term, the pandemic has exposed fundamental weaknesses in both social care and public health. Social care has been neglected by successive governments, all of which have favoured sticking plaster solutions to sustainable reform. This was seen in November's spending review when the government announced some extra funding to shore up the current system but gave no indication of when its long delayed green paper on social care might be published.

The virus has also exposed wide and persistent inequalities in health that have been accentuated by cuts to public health budgets. The differential effect of the pandemic on ethnic minority groups and deprived communities underlines the deep roots of health inequalities and the need for a comprehensive programme of action if levelling up is to be more than an empty slogan. Marmot and colleagues have outlined what such a programme should contain, but whether the government has the will to act on their recommendations remains to be seen. ${ }^{3}$

As the time honoured phrase goes, a good crisis should never go to waste. What, then, are the implications for the NHS and its partners? NHS England set out its views in guidance for both the NHS and local government on 23 December. It urged local leaders to focus on "pulling out all the stops to implement the covid-19 vaccination programme" and "maximising capacity in all settings to treat non-covid-19 patients" for the remainder of 2020 and 2021, while also beginning to plan for 2021-22. ${ }^{4}$

These injunctions are necessary. They are unlikely to be sufficient. A more ambitious vision is needed, building on the many innovations introduced in recent months by staff who have found solutions to the problems they have encountered. The most important national priority is a properly resourced workforce strategy, which should be the centrepiece of an updated long term plan for the NHS, revisiting priorities set out in 2019 and taking into account the effects of the pandemic. ${ }^{5}$

Beyond the NHS, the government must set out credible commitments on social care and health inequalities. Increased public spending to deliver care services to an acceptable standard and to tackle the fragility of the social care market is a minimum requirement. Closer integration with the NHS is essential, along with greater alignment of entitlements to health and social care.

Health inequalities require action across government, starting with the early years and extending to fair employment and living standards, underpinned by a stronger focus on prevention and reconstruction of the depleted public health system. Local authorities should work with their partners in the public and private sectors to develop solutions appropriate to their areas through greater devolution of decision making from Whitehall.

Some might say that reforms of this kind are unaffordable with the level of government debt that has built up in response to covid-19. But neither tinkering nor measures merely to restore the health and care system to its pre-covid status will do. Only a programme with an ambition that matches the scale of current challenges will enable the NHS to cope with immediate and intense pressures and build back better for the future.

Lintern S. Number of people on NHS waiting lists hits 12-year high. Independent 2020 Dec 10. https://www indepen-

dent.co.uk/news/health/nhs-waiting-times-surgery-patients-b1769206.html 
2 Centre for Mental Health. Covid-19 and the nation's mental health. Oct 2020 https://www.centreformentalhealth.org.uk/publications/covid-19-and-nations-mental-health-october-2020

3 Marmot M, Allen J, Goldblatt T, Herd E, Morrison J. Build back fairer. the covid-19 Marmot review 2020 https://www.health.org.uk/publications/build-back-fairer-the-covid-19-marmot-review

4 Pritchard A, Kelly J. Important-for action-operational priorities for winter and 2021/22. NHS England. 2020 https://www.england.nhs.uk/coronavirus/publication/important-operational-priorities-for-winter-and-2021-22/

5 NHS. The NHS long-term plan. 2019 https://www.longtermplan.nhs.uk/publication/nhs-long-termplan/

This article is made freely available for use in accordance with BMJ's website terms and conditions for the duration of the covid-19 pandemic or until otherwise determined by BMJ. You may use, download and print the article for any lawful, non-commercial purpose (including text and data mining) provided that all copyright notices and trade marks are retained. 